\title{
Comparison of the craniometric parameters of wild and farm American mink (Mustela vison)
}

\author{
M. Taraska1, M. Sulik², B. Lasota ${ }^{3}$ \\ ${ }^{1}$ Department of Animal Anatomy, West Pomeranian University of Technology, Szczecin Faculty of Biotechnology \\ and Animal Husbandary, Szczecin, Poland \\ ${ }^{2}$ Laboratory of Fur Animal Breeding, West Pomeranian University of Technology, Szczecin Faculty of Biotechnology \\ and Animal Husbandary, Szczecin, Poland \\ ${ }^{3}$ Department of Biotechnology of Animal Reproduction and Environmental Hygiene, West Pomeranian University \\ of Technology, Szczecin Faculty of Biotechnology and Animal Husbandary, Szczecin, Poland
}

[Received: 19 July 2015; Accepted: 14 September 2015]

Skulls of 65 American minks from the West Pomeranian Province were examined (farm: $n=33$, male: $n=16$, female: $n=17$; wild: $n=32$, male: $n=20$, female: $n=12)$. Craniometric parameters in the number of 24 were determined and measured on each skull. Results were averaged and compared, maintaining the division into sex groups. Males were found to have statistically significant differences between wild and farm animals in 20 parameters; measurements showing no statistically significant differences were: nasal length, postorbital constriction, brain case height and greatest height of the mandibular body. Females were found to have statistically significant differences between wild and farm animals in 6 parameters: condylobasal length, tooth row length, greatest length of the mandible, brain case basis length, postorbital length and palatal length. The percentage conversion of measurements into the greatest length of the skull showed differences in its proportions. Among male skulls, the parameters for which the ratio of differences was more than $2 \%$ were palatal length, zygomatic breadth and brain case height. For female skulls, no craniometric parameters showed differences in the skull proportions being greater than $2 \%$. The occurrence of measurable changes in the craniometric parameters between domestic and farm mink populations may indicate that the domestication process is still ongoing and allows distinguishing the population affiliation of an individual specimen. (Folia Morphol 2016; 75, 2: 251-256)

Key words: morphology, skull anatomy, domestication changes, fur animals

\section{INTRODUCTION}

American mink (Mustela vison/Neovison vison) is characterised by coat durability and high degree of coat alignment over the whole body [11]. Because of the above features, American mink has become a target of the human interest as a fur animal. The import of American minks for farming purposes to areas that were not its natural habitats has extended the range of its occurrence. Currently, wild mink is found in North America, Europe and Asia [8]. It is believed that animals inhabiting the Old World countries, including Poland, are the descendants of escaped farm animals and those being introduced in the former Soviet Union, Belarus and Asian countries in the mid-twentieth century [3].

Address for correspondence: mgr inż. M. Taraska, Department of Animal Anatomy, West Pomeranian University of Technology, Szczecin Faculty of Biotechnology and Animal Husbandary, ul. Doktora Judyma 14, 71-466 Szczecin, Poland, tel: +48 914496742 , fax: +48 914496740 , 
Animal species subjected by the man to organised breeding undergo a series of processes and changes known as domestication. Domestication is not a point phenomenon - it isn't possible to describe the turning point when a wild species becomes a domesticated one. This is a continuous process of converting the wild form into a farm one which is the result of selection and influence of farming_conditions on next generations of animals [9].

Under the influence of domestication processes, changes in similar features in different species were observed: body size changes in relation to non-domestic form, occurrence of colour varieties, disappearance of seasonal reproduction patterns and behavioural changes [5]. In many species, there were reductions in the brain and the facial skeleton and the differences in the shape of bones, mainly in the expression of bony projections and depressions [14]. American mink is no exception to this rule - an organised breeding has had a huge impact on this species and, although the process of mink domestication is still ongoing, highly visible differences between farmed minks and their wild relatives have been noticed. Changes have been featured in many traits (size, weight) and, above all, an increase in the diversity of coat colour [13]. The aim of this study was to compare the skulls of wild and farm minks and to determine whether there are differences that allow classification of individual animals into those belonging to the population of farm or wild animals.

\section{MATERIALS AND METHODS}

In this study, the skulls of 65 adult American minks were used: 33 domestic ( 16 male and 17 female) and 32 wild (20 male and 12 female). The material from farm animals was collected from farms in the West Pomeranian Province; that representing wild animals came from the individuals being caught in the same region of the country. Wild animals were caught with bait traps in the area that was at least $50 \mathrm{~km}$ away from the nearest mink farm.

From the obtained carcasses, heads were dissected. They were cleaned by removing soft tissues being previously subjected to heat treatment. Next, the skulls were bathed in a 30\% hydrogen peroxide solution (Perhydrol ${ }^{\circledR}$ ) for approximately $15 \mathrm{~min}$.

Measurements were performed using a mixed method, based on 3 measuring methods presented by Kruska and Sidorovich [10], Jakubowski et al. [7] and von den Driesch [4]. Measurements were made with an electronic calliper with accuracy of $0.1 \mathrm{~mm}$.
The volume of the cranium was measured using millet grains (1.4-1.6 mm diameter) and a $20 \mathrm{~cm}^{3}$ measuring cylinder. Each measurement was repeated 3 times and averaged.

The following measurements of 24 craniometric parameters were taken: $\mathrm{CBL}$ - condylobasal length (greatest length of the skull); PAL - palatal length; $\mathrm{BBL}$ - brain case basis length; TRL - tooth row length; $\mathrm{BCL}$ - brain case length; NAL — nasal length; $\mathrm{POL}$ - postorbital length; $\mathrm{BRC}$ - breadth across the canines; $\mathrm{IOC}$ - interorbital constriction; $\mathrm{POC}$ - postorbital constriction; JUB - jugal (zygomatic) breadth; $\mathrm{MAB}$ - mastoid breadth; $\mathrm{BCH}$ - brain case height; FSH - frontal skull height; $\mathrm{CSH}$ - caudal skull height; $\mathrm{BCS}$ - brain case size; Id-Goc - greatest length of the mandible; Gov- $\mathrm{Cr}$ - height of the mandibular ramus; $\mathrm{HM}_{1}$ - greatest height of the mandibular body; $\mathrm{HP}_{1} \mathrm{P}_{2}$ - height of the mandibular body between $\mathrm{P} 1$ and P2; Mol-Mol - greatest breadth across the alveoli for $\mathrm{M} 1$; $\mathrm{BC}$ - breadth across the alveoli for mandibular canines; BCP - greatest breadth of the condylar process; GBR - greatest breadth across the mandibular rami - maximum breadth of two mandibles.

The values obtained for these measurements are summarised in tables. The results were statistically analysed by calculating average values and percentages of individual parameters in the greatest length of the skull. The significance of differences between groups was examined by Duncan's test $(p \leq 0.01)$ using StatSoft Statistica 10 computer software.

\section{RESULTS}

As a result of the conducted study, significant differences in the American mink skull morphometry were found, both between average values for all animals and those for particular sex groups. Statistically significant differences between the measurements for all animals were found in 6 parameters: CBL, PAL, TRL, Id-Goc, $\mathrm{HP}_{1} \mathrm{P}_{2}$ and $\mathrm{BC}$. These measurements had higher values for farm minks (Table 1).

Females were found to have statistically significant differences in 6 parameters: CBL, PAL, BBL, TRL, POL and Id-Goc. These measurements were higher for farm minks (Table 2).

Significant differences between the measurements for males were found in 20 parameters. The parameters for which measurements showed no statistically significant differences were: NAL, POC, BCH and $\mathrm{HM}_{1}$. Statistically significant higher values were found in the group of farm minks (Table 3 ). 
Table 1. Average values of the craniometric measurements for wild and farm mink skulls, both sexes included (in $\mathrm{mm}, \mathrm{cm}^{3}$ )

\begin{tabular}{lcccccc}
\hline Both sexes & CBL & PAL & BBL & TRL & BCL & NAL \\
\hline Wild & $66.36 \mathrm{~A}$ & $27.62 \mathrm{~B}$ & 31.87 & $23.24 \mathrm{C}$ & 34.81 & 16.59 \\
Farm & $70.49 \mathrm{~A}$ & $30.38 \mathrm{~B}$ & 33.15 & $24.86 \mathrm{C}$ & 36.04 & 16.65 \\
\hline Both sexes & POL & BRC & IOC & POC & JUB & MAB \\
\hline Wild & 43.87 & 14.02 & 15.04 & 12.68 & 38.22 & 34,32 \\
Farm & 46.12 & 14.37 & 15.39 & 12.72 & 39.00 & 35.18 \\
\hline Both sexes & BCH & FSH & CSH & Id-GoC & Gov-Cr & HM $_{1}$ \\
\hline Wild & 20.48 & 15.73 & 23.15 & 38.20 D & 18.66 & 8.18 \\
Farm & 20.28 & 16.42 & 23.96 & $40.72 \mathrm{D}$ & 19.53 & 7.99 \\
\hline Both sexes & HP.P & Mol-Mol & BC & BCP & GBR & BCS [cm $\left.{ }^{3}\right]$ \\
\hline Wild & $6.64 \mathrm{E}$ & 17.47 & $7.72 \mathrm{~F}$ & 10.46 & 25.44 & 9.54 \\
Farm & $7.16 \mathrm{E}$ & 17.66 & $8.40 \mathrm{~F}$ & 10.70 & 26.06 & 10.09 \\
\hline
\end{tabular}

Letters show statistically significant differences at $\mathrm{p} \leq 0.01$; abbreviations - see text

Table 2. Average values of the craniometric measurements for farm and wild female mink skulls (in $\mathrm{mm}, \mathrm{cm}^{3}$ )

\begin{tabular}{lcccccc}
\hline Females & CBL & PAL & BBL & TRL & BCL & NAL \\
\hline Wild & $61.94 \mathrm{~A}$ & $25.59 \mathrm{~B}$ & $29.91 \mathrm{C}$ & $21.74 \mathrm{D}$ & 32.45 & 15.57 \\
Farm & $65.83 \mathrm{~A}$ & $27.76 \mathrm{~B}$ & $31.24 \mathrm{C}$ & $23.30 \mathrm{D}$ & 33.73 & 15.88 \\
\hline Females & POL & BRC & IOC & POC & JUB & MAB \\
\hline Wild & $40.76 \mathrm{E}$ & 12.78 & 13.78 & 11.80 & 34.85 & 31.47 \\
Farm & $42.68 \mathrm{E}$ & 13.22 & 14.14 & 12.35 & 35.76 & 32.38 \\
\hline Females & BCH & FSH & CSH & Id-Goc & Gov-Cr & HM $_{1}$ \\
\hline Wild & 18.91 & 14.47 & 21.57 & $35.02 \mathrm{~F}$ & 16.77 & 7.33 \\
Farm & 18.83 & 15.06 & 22.35 & $37.34 \mathrm{~F}$ & 17.59 & 7.20 \\
\hline Females & HP.P & Mol-Mol & BC & BCP & GBR & BCS [cm $\left.{ }^{3}\right]$ \\
\hline Wild & 6.18 & 16.21 & 7.14 & 9.53 & 23.58 & 8.13 \\
Farm & 6.45 & 16.37 & 7.77 & 9.62 & 24.22 & 8.92 \\
\hline
\end{tabular}

Letters show statistically significant differences at $p \leq 0.01$; abbreviations - see text

Table 3. Average values of the craniometric measurements for farm and wild male mink skulls (in $\mathrm{mm}, \mathrm{cm}^{3}$ )

\begin{tabular}{lcccccc}
\hline Males & CBL & PAL & BBL & TRL & BCL & NAL \\
\hline Wild & $69.02 \mathrm{~A}$ & $28.84 \mathrm{~B}$ & $33.05 \mathrm{C}$ & $24.14 \mathrm{D}$ & $36.22 \mathrm{E}$ & 17.21 \\
Farm & $75.44 \mathrm{~A}$ & $33.17 \mathrm{~B}$ & $35.19 \mathrm{C}$ & $26.53 \mathrm{D}$ & $38.50 \mathrm{E}$ & 17.48 \\
\hline Males & POL & BRC & IOC & POC & JUB & MAB \\
\hline Wild & $45.73 \mathrm{~F}$ & $14.76 \mathrm{G}$ & $15.80 \mathrm{H}$ & 13.20 & $40.25 \mathrm{I}$ & $36.03 \mathrm{~J}$ \\
Farm & $49.78 \mathrm{~F}$ & $15.58 \mathrm{G}$ & $16.72 \mathrm{H}$ & 13.10 & $42.43 \mathrm{I}$ & $38.16 \mathrm{~J}$ \\
\hline Males & BCH & FSH & CSH & Id-Goc & Gov-Cr & HM $_{1}$ \\
\hline Wild & 21.43 & $16.49 \mathrm{~K}$ & $24.10 \mathrm{~L}$ & $40.11 \mathrm{M}$ & $19.80 \mathrm{~N}$ & 8.70 \\
Farm & 21.82 & $17.86 \mathrm{~K}$ & $25.66 \mathrm{~L}$ & $44.33 \mathrm{M}$ & $21.58 \mathrm{~N}$ & 8.83 \\
\hline Males & HP.P & Mol-Mol & BC & BCP & GBR & BCS [cm $\left.{ }^{3}\right]$ \\
\hline Wild & 6.920 & $18.22 \mathrm{P}$ & $8.06 \mathrm{R}$ & $11.02 \mathrm{~S}$ & $26.56 \mathrm{~T}$ & $10.38 \mathrm{U}$ \\
Farm & 7.930 & $19.04 \mathrm{P}$ & $9.06 \mathrm{R}$ & $11.85 \mathrm{~S}$ & $28.02 \mathrm{~T}$ & $11.33 \mathrm{U}$ \\
\hline
\end{tabular}

Letters show statistically significant differences at $p \leq 0.01$; abbreviations - see text 
Table 4. Percentages of individual craniometric measurements for wild and farm mink skulls in relation to the greatest length of the skull (\%)

\begin{tabular}{lcccccc}
\hline Both sexes & CBL & PAL & BBL & TRL & BCL & NAL \\
\hline Wild & 100 & 41.62 & 48.03 & 35.02 & 52.46 & 25.00 \\
Farm & 100 & 43.10 & 47.03 & 35.27 & 51.13 & 23.62 \\
\hline Both sexes & POL & BRC & IOC & POC & JUB & MAB \\
\hline Wild & $61.42^{*}$ & 21.13 & 22.66 & 19.11 & $57.59^{*}$ & 51.72 \\
Farm & $65.43^{*}$ & 20.39 & 21.83 & 18.05 & $55.33^{*}$ & 49.91 \\
\hline Both sexes & BCH & FSH & CSH & Id-Goc & Gov-Cr & HM \\
\hline Wild & $30.86^{*}$ & 23.70 & 34.89 & 57.57 & 28.12 & 12.33 \\
Farm & $28.77^{*}$ & 23.29 & 33.99 & 57.77 & 27.71 & 11.34 \\
\hline Both sexes & HP. $_{\mathbf{1}}$ & Mol-Mol & BC & BCP & GBR & BCS [cm $\left.{ }^{3}\right]$ \\
\hline Wild & 10.01 & 26.33 & 11.63 & 15.76 & 38.34 & 14.38 \\
Farm & 10.16 & 25.05 & 11.92 & 15.18 & 36.97 & 14.31 \\
\hline
\end{tabular}

${ }^{*}$ Asterisk indicates a difference of more than $2 \%$; abbreviations - see text

Table 5. Percentages of individual craniometric measurements for wild and farm female mink skulls in relation to the greatest length of the skull (\%)

\begin{tabular}{lcccccc}
\hline Female & CBL & PAL & BBL & TRL & BCL & NAL \\
\hline Wild & 100 & 41.31 & 48.29 & 35.1 & 52.39 & 25.14 \\
Farm & 100 & 42.17 & 47.46 & 35.39 & 51.24 & 24.12 \\
\hline Female & POL & BRC & IOC & POC & JUB & MAB \\
\hline Wild & 65.81 & 20.63 & 22.25 & 19.05 & 56.26 & 50.81 \\
Farm & 64.83 & 20.08 & 21.48 & 18.76 & 54.32 & 49.19 \\
\hline Female & BCH & FSH & CSH & Id-GoC & Gov-Cr & HM \\
\hline Wild & 30.53 & 23.36 & 34.82 & 56.54 & 27.07 & 11.83 \\
Farm & 28.6 & 22.88 & 33.95 & 56.72 & 26.72 & 10.94 \\
\hline Female & HP. & Mol-Mol & BC & BCP & GBR & BCS [cm $\left.{ }^{3}\right]$ \\
\hline Wild & 9.98 & 26.17 & 11.53 & 15.39 & 38.1 & 13.13 \\
Farm & 9.8 & 24.87 & 11.8 & 14.61 & 36.79 & 13.55 \\
\hline
\end{tabular}

Abbreviations - see text

The percentage conversion of measurements to the greatest length of the skull showed differences in its proportions. In further analysis, only the parameters for which a difference in the skull proportions exceeded $2 \%$ were considered. For the whole group of wild and farm minks, differences that exceeded $2 \%$ were found in 3 parameters only: POL, JUB and $\mathrm{BCH}$. The first parameter was characterised by larger contribution in the greatest length of the skull in farm minks, whereas the other 2 parameters were characterised by larger contribution in the greatest length of the skull in the group of wild minks (Table 4).
In females, there were no craniometric parameters for which differences in the skull proportions were greater than $2 \%$ (Table 5).

In males, the parameters for which differences in the skull proportions were higher than $2 \%$ were as follows: $\mathrm{PAL}, \mathrm{JUB}$ and $\mathrm{BCH}$. The first parameter was characterised by larger contribution in the greatest length of the skull in farm minks, whereas the other 2 parameters were characterised larger contribution in the greatest length of the skull in the group of wild minks (Table 6).

\section{DISCUSSION}

Herre and Röhrs [6] have stated that domestication is a process which may lead even to very signifi- 
Table 6. Percentages of individual craniometric measurements for wild and farm male mink skulls in relation to the greatest length of the skull (\%)

\begin{tabular}{lcccccc}
\hline Male & CBL & PAL & BBL & TRL & BCL & NAL \\
\hline Wild & 100 & $41.78^{*}$ & 47.88 & 34.98 & 52.48 & 24.93 \\
Farm & 100 & $43.97^{*}$ & 46.65 & 35.17 & 51.03 & 23.17 \\
\hline Male & POL & BRC & IOC & POC & JUB & MAB \\
\hline Wild & 66.27 & 21.39 & 22.89 & 19.12 & $58.32^{*}$ & 52.20 \\
Farm & 65.99 & 20.65 & 22.16 & 17.36 & $56.24^{*}$ & 50.58 \\
\hline Male & BCH & FSH & CSH & Id-GoC & Gov-Cr & HM $_{1}$ \\
\hline Wild & $31.05^{*}$ & 23.89 & 34.92 & 58.11 & 28.69 & 12.61 \\
Farm & $28.92^{*}$ & 23.67 & 34.01 & 58.76 & 28.61 & 11.70 \\
\hline Male & HP $_{\mathbf{1}} \mathbf{P}_{2}$ & Mol-Mol & BC & BCP & GBR & BCS [cm $\left.{ }^{3}\right]$ \\
\hline Wild & 10.03 & 26.40 & 11.68 & 15.97 & 38.48 & 15.04 \\
Farm & 10.51 & 25.24 & 12.01 & 15.71 & 37.14 & 15.02 \\
\hline
\end{tabular}

${ }^{*}$ Asterisk indicates a difference of more than $2 \%$; abbreviations — see text

cant changes in almost all biological traits, including skeletal parameters. The study conducted for the purpose of this paper shows the presence of differences in craniometric characteristics between wild and farm populations of American mink.

One of the most characteristic changes being observed is a general increase in the skull dimensions in the farm population. Tamlin et al. [14] report that a change in the size of the skull is one of the most reliable parameters to distinguish its origin. The genesis of this change might be sought in selection for larger body size, i.e. to give the fur coat a better market value, as well as in no need to spend lots of energy for foraging which results in better supply of nutrients to the body. In their study, Lynch and Hayden [12] also point out to genetic determination of body size, which is associated with corresponding genes for coat colour. Similar results were obtained by Baranowski et al. [1] who found a relationship between the size and shape of the skull and the colour variant of American minks.

In their study, Tamlin et al. [14] observe no significant changes in the proportions of craniometric parameters between wild and farm minks, except a narrowing in the POC. This is contrary to the results obtained in this study. Changes in the skull proportions were observed for the whole group of wild and farm minks in 3 parameters: POL, JUB and $\mathrm{BCH}$. Among males, these changes occurred in the PAL, JUB and $\mathrm{BCH}$. These results are similar to those being obtained by Kruska and Sidorovich [10] who show a narrowing of JUB and MAB. However, Kruska and Sidorovich [10] pointed out first of all to the reduction of brain case volume being associated with changes in behaviour and deterioration of sense organs as a consequence of domestication processes. On the other hand, the results obtained in this study do not show a reduction in the brain case volume in farm animals.

Bowman et al. [2] are of the opinion that the lack of brain volume reduction in farm minks may be associated with the uncertain status of wild minks used in their study. If there are the descendants of escapees from farms among the wild population, their craniometric characteristics will oscillate towards the values being found for the parameters of farm minks.

Changes in the proportion of craniometric parameters in relation to the greatest length of the skull never exceeded the value of the $4 \%$ in the examined populations. This is a relatively low level of differentiation, which may result from the origin of wild mink population in Poland. It is widely believed that wild individuals living in different areas of our country are descendants of escapees from mink farms and animals that were introduced into the former Soviet Union and Belarus in the mid-twentieth century. Kruska and Sidorovich [10] argue that skeletal changes are permanent and their reversibility, which is a very slow process, is small. Wild mink population inhabiting Poland, which has its origins in farm animals, may have a skull structure similar to that of farm minks. 


\section{CONCLUSIONS}

The results obtained in this study show the presence of statistically significant differences in craniometric parameters and measurable changes in the skull proportions between wild and farm mink populations. This suggests that the domestication process is still in progress. This diversity enables determination of the population affiliation of a specimen based on the structure of its skull.

\section{ACKNOWLEDGEMENTS}

This work was financed by NCBiR Grant Number 12-0140-10.

\section{REFERENCES}

1. Baranowski P, Pezinska-Kijak K, Felska-Blaszczyk L, Zuk K, Nowak P, Kosecka J, Oczeretko K, Chukwu P, Mazur P (2014) An attempt to determine the size of biometric differences in the skull of two colour variants of American mink (Neovison vison). Int J Morphol, 32: 895-8901. doi: 10.4067/S0717-95022014000300024.

2. Bowman J, Kidd AG, Gorman RM, Schulte-Hostedde Al (2007) Assessing the potential for impacts by feral mink on wild mink in Canada. Biol Conversation, 139: 12-18. doi: 10.1016/j.biocon.2007.05.020.

3. Cholewa R (2000) Rearing and breeding of fur animals. [in Polish]. Wyd. Akademiia Rolnicza, Poznań.

4. Driesch A (1976) A guide to measurement of animal bones from archeological sites. Peabody Museum of Archaeology and Ethnology, Harvard University.
5. Felska-Błaszczyk L, Baranowski P, Seremak B, Pęzińska K, Nowak P, Lasota B, Steller O (2013) Domestication of the red fox (Vulpes Vulpes) reflected in metric characters of selected thoracic girdle bones. Acta Sci Pol Zootechnica, 12: 15-30.

6. Herre W, Röhrs M (1990) Haustiere - zoologisch gesehen. 2nd Ed. Gustav Fischer, Stuttgart, New York.

7. Jakubowski H, Komosa M, Frąckowiak H (2008) Allometric analysis of cranial parameters of American mink, including bones of masticatory apparatus. Electr J Polish Agricultural Univers, EJPAU, 11: 2.

8. Jarosz S (1993) Breeding of fur animals [in Polish]. Wyd. PWN, Warszawa-Kraków.

9. Kowalska D, Gugołek A (2013) Domestication changes and behavioural indicators of fur animal adaptation [in Polish]. Wiadomości Zootechniczne, R.LI, 1: 31-40.

10. Kruska DCT, Sidorovich VE (2003) Comparative allometric skull morphometrics in mink (Mustela vison Schreber 1777) of Canadian and Belarus origin; taxonomic status. Mammalian Biology (Zeitschrift für Säugetierkunde), 68: 257-276. doi: 10.1078/1616-5047-00095.

11. Lisiecki H, Sławoń J (1980) Mink breeding [in Polish]. PWRiL, Warszawa.

12. Lynch JM, Hayden TJ (1995) Genetic influences on cranial form: variation among ranch and feral American mink Mustela vison (Mammalia: Mustelidae). Biol J Linnean Society, 55: 293-307. doi: 10.1111/j.1095-8312.1995.tb01067.x.

13. Piórkowska M, Kowalska D (2014) Characteristics of farmed and wild populations of American mink [in Polish]. Wiadomości Zootechniczne, R. LII, 2: 122-129.

14. Tamlin AL, Bowman J, Hackett DF (2009) Separating wild from domestic American mink Neovison vison based on skull morphometrics. Wildlife Biol, 15: 266-277. doi: 10.2981/08-004. 